\title{
W. BROOKER Y D. JERMYR (eds.), The audience studies reader, Routledge: Londres y Nueva York, 2003
}

Como indica el propio título de la obra, colección de trabajos que abordan, desde distintas perspectivas, un concepto tan polimórfico como la audiencia. Con una evidente finalidad académica, se articulan fragmentos clásicos, aun cuando habría que hablar de fragmentos de obras e investigaciones clásicas, con nuevas aportaciones o lo que cabe denominar puesta al día.

Los títulos de las partes en que está dividida la obra, ya dan idea del panorama poliédrico que presenta en la actualidad la investigación de audiencias y, a su vez, la intención de abarcarlo. Con tal punto de partida y tal horizonte, no resulta extraño el amplio volumen del texto, en el que se acumulan treinta y tres trabajos distintos.

El inicio de su composición tiene un corte que más que clásico, tal vez sea más conveniente denominarlo estandarizado. El primero paso se da con una selección de textos que condensan teorías como la de los efectos y la de usos y gratificaciones. Se vuelven a recuperar, una vez más, fragmentos de la investigación dirigida por Lazarsfeld The People's Choice y del Mass persuasión de Merton. Es decir, clásicos que rozan el carácter de instituciones en el campo de estudio.

El siguiente paso, cuyo título es el expresivo $\ll \mathrm{La}$ vulnerabilidad de la audiencia», recoge trabajos desde el estudio sobre el pánico a la reflexión sobre el dominio de la industria cultural. Desde Adorno hasta un fragmento de la también conocida investigación empírica sobre el uso de los medios que realizan las clases populares y obreras británicas de Hoggart. Si en el primer paso dominaba la derecha ideológica, aquí se refugian algunas de las distintas visiones críticas originarias de la investigación de audiencias.
Una crítica que se prolonga en el siguiente apartado, concentrado en la concepción de la recepción como resistencia, al que puede considerarse, salvo en el caso de Hoggart que adquiere el papel de puente entre la anterior posición crítica y ésta, como una especie de negación de la negación o, para entendernos, lecturas críticas de las reacciones críticas de los anteriores. Aquí volvemos a encontrarnos también con trabajos ampliamente difundidos en el campo, que también rozan la categoría de clásicos. Son los de Morley, de Certeau, para quien la entusiasta recepción norteamericana tras su fallecimiento parece inagotable y Fiske, que, conviene subrayarlo aquí, es el que da certifica la identificación de recepción con resistencia. No obstante, conviene destacar, en línea ideológica semejante al grupo que le ha tocado compartir, el menos conocido trabajo de Woods sobre la publicidad.

En la cuarta parte, el cine es el protagonista. Muy pertinente un apartado a un medio de comunicación que parece no encontrarse ya entre los que se consideran masivos y, por lo tanto, sobre los que con mayor intensidad y ahínco se centra la investigación de audiencias. Destacan aquí los trabajos de Mulvey, Hansen y Stacey.

La televisión recupera su protagonismo con el apartado dedicado a los fans y los programas de culto. La parte con menor concentración de trabajos clásicos $y$, seguramente, la que genera mayor frustración. Tal vez sea porque, por su carácter novedoso, genera más expectativas. En cualquier caso, se trata de una recepción muy particular, que va más allá de la relación con la pantalla, al mismo ritmo que la sociología de la comunicación se convierte en un plato que combina socio- 
logía del consumo y sociología de la religión. Tres campos -comunicación, consumo y religión- que no se encuentran tan separados y cuya conexión nos recuerda una especie de unidad metodológica de la sociología.

La sola nominación de apellidos como Radway, Ang o McRobbie sitúa al especialista en el campo en su relación con los estudios de género. Tal vez no están todas las que son, algo lógico en una obra que es una selección; pero, desde luego, sí son todas las que están. Las investigaciones sobre audiencia femenina presentadas se inscriben preferentemente en el ámbito de los estudios culturales, corriente que, tal vez por su amplitud ( $y$ ambigüedades) es dominante en el balance del texto.

La última parte, antes de alcanzar las conclusiones, extiende el concepto de audiencia al de comunidad. La referencia a las comunidades interpretativas incluye el trabajo de Liebes y Katz sobre las diferencias a la hora de recibir el mismo mensaje -la popular serie Dallas- en distintas partes del mundo y, sobre todo, entre distintas comunidades étnicas. Ejemplo de cómo la interpretación diferencial puede reconstruir los argumentos de un mensaje de ficción hasta hacerlos prácticamente irreconocibles por otra comunidad distinta, incluyendo la comunidad creadora del mensaje. Investigación que, también, ha provocado a lo largo del tiempo distintas discusiones metodológicas. Cabe citar en este apartado las contribuciones de Bobo y Gillespie. No obstante, la lectura de tales aportaciones deja en el aire la pregunta de hasta donde puede llegar el concepto de comunidad. Desde luego, a veces se tiene la sensación de que se le fuerza en demasía, hasta llegar a desfigurarlo.

El conjunto de la obra constituye un magnífico material para introducirse en el campo de la investigación de audiencias. Especialmente si tal introducción se propone a alumnos de las titulaciones rela- cionadas con la comunicación o con la sociología. Pero, como ocurre en toda selección, dista de una perfección imposible. Aquí se ha optado por una amplia variedad y un repaso general, desde las investigaciones clásicas a las preocupaciones actuales. Ambas decisiones han tenido que pagar su canon. La primera en forma de textos recortados, incompletos, que, en algunos casos, habría que tomar como invitaciones al texto completo de donde se ha extraído lo publicado en la selección.

El segundo canon es el escaso espacio dejado a los denominados nuevos medios. Es más, éstos pueden llegar a plantear, dadas las particulares condiciones de comunicación que proponen, otra forma de plantear la investigación de audiencias. Algo que parcialmente se recoge en las conclusiones. Dentro del apartado de nuevas tendencias de la investigación de audiencias, aparece un tema que adquiere precisamente la categoría de fantasma que puede llegar a transformar radicalmente la manera de entender las audiencias. Es la televisión participativa $\mathrm{y}$, por lo tanto, su correlato: la audiencia participativa. Algo que se sitúa bajo la atractiva categoría de web cultura, como si fuese la cultura derivada de Internet y sus entornos lo que producirá otro tipo de audiencia que, a su vez, generará otro tipo de comunicación. Tema que se convierte en fantasma cuando se observa desde la perspectiva de la supuesta extensión del enganche de la audiencia. De una audiencia, poniéndose el ejemplo de programas como Gran Hermano, que decide el desarrollo y desenlace del programa. Incluso se llega a hablar de medios realizados por su audiencia en el caso de los informativos. Es como si la audiencia traspasase el espejo. La pena es que todo este tipo de reflexiones, $\tan$ actuales como interesantes, se reservan a unas pocas líneas en el capítulo de conclusiones. Tal vez, una indicación de que 
la forma en las que se han entendido las audiencias a lo largo de estos años y que constituyen el núcleo de la obra ha dejado de tener sentido. Quizá, una invitación a una futura y próxima selección de fragmentos que aborden estas direcciones de la audiencia. Sobre todo, teniendo en cuenta que serán principalmente alumnos los receptores de The audience studies reader, la propuesta de un reto para tales receptores: pensar nuevamente las audiencias de la comunicación mediada.

Javier Callejo 